\title{
Toward the Identification of Consumer Retailer Nostalgia: An Abstract
}

\author{
Hyunju Shin and Janna M. Parker
}

\begin{abstract}
While nostalgia has received considerable attention in the marketing literature, relatively little research has been conducted as to the role of consumer nostalgia in the retail setting. In addition, while previous research has found that autobiographical memories are evoked naturally and spontaneously in response to various marketing stimuli and many consumption memories involve retail experiences, little is known about the types of nostalgic memories evoked by remembering a retailer and the elements of retailing that are associated with such memories.

In this research, a projective technique involves the creation of a collage of a specific retailer selected by the participant which utilized images with written descriptions that represented the participant's experiences with the selected retailer. Judges conducted a content analysis of the collages $(n=105)$. The results provided a basis to identify, categorize, and define the distinct types of retailer-related nostalgic memories and the elements of retailing experiences that contribute to nostalgic memories.
\end{abstract}

References Available Upon Request

H. Shin

Georgia Southern University, Statesboro, GA, USA

e-mail: hshin@georgiasouthern.edu

J.M. Parker $(\varangle)$

James Madison University, Harrisonburg, VA, USA

e-mail: parke4jm@jmu.edu 